\title{
Dynamical Downscaling of Climate Change Impacts on Wind Energy Resources in the Contiguous United States by Using a Limited-Area Model with Scale-Selective Data Assimilation
}

\author{
Bin Liu, Katelyn B. Costa, Lian Xie, and Fredrick H. M. Semazzi \\ Department of Marine, Earth and Atmospheric Sciences (MEAS), North Carolina State University (NCSU), \\ Campus Box 8208, Raleigh, NC 27695, USA \\ Correspondence should be addressed to Bin Liu; bliu5@ncsu.edu
}

Received 18 May 2014; Revised 28 July 2014; Accepted 4 August 2014; Published 22 September 2014

Academic Editor: Adel Hanna

Copyright (C) 2014 Bin Liu et al. This is an open access article distributed under the Creative Commons Attribution License, which permits unrestricted use, distribution, and reproduction in any medium, provided the original work is properly cited.

By using a limited-area model (LAM) in combination with the scale-selective data assimilation (SSDA) approach, wind energy resources in the contiguous United States (CONUS) were downscaled from IPCC CCSM3 global model projections for both current and future climate conditions. An assessment of climate change impacts on wind energy resources in the CONUS region was then conducted. Based on the downscaling results, when projecting into future climate under IPCC's A1B scenario, the average annual wind speed experiences an overall shift across the CONUS region. From the current climate to the 2040s, the average annual wind speed is expected to increase from 0.1 to $0.2 \mathrm{~m} \mathrm{~s}^{-1}$ over the Great Plains, Northern Great Lakes Region, and Southwestern United States located southwest of the Rocky Mountains. When projecting into the 2090s from current climate, there is an overall increase in the Great Plains Region and Southwestern United States located southwest of the Rockies with a mean wind speed increase between 0 and $0.1 \mathrm{~m} \mathrm{~s}^{-1}$, while, the Northern Great Lakes Region experiences an even greater increase from current climate to 2090s than over the first few decades with an increase of mean wind speed from 0.1 to $0.4 \mathrm{~m} \mathrm{~s}^{-1}$.

\section{Introduction}

The specific purpose of this study is to investigate the impacts of climate change on wind energy resources over the continental United States (CONUS). Climate change is constantly altering wind patterns across the globe. Wind is an extremely valuable renewable energy source that needs to receive significantly greater attention as earth's climate continues to change. The focus of this study will be to project where the best possible wind energy sources will be located throughout the CONUS, in order to get the maximum possible usage of wind energy in the future.

Under current climate, according to the National Renewable Energy Laboratory of the US Department of Energy, the superb or best places/location in the CONUS region for wind resource potential is found just offshore along the west coast by Northern California and Southern Oregon. Also, the midwestern states, Montana, Wyoming, Colorado, and New Mexico, all contain superb wind energy resource potential. The outstanding or second-to-best locations across the CONUS region for wind resource potential are found along the east coast extending from Maine to South Carolina, within the Great Lakes Region, and along areas of the west coast just offshore Washington State, Northern Oregon, and mid- and Southern California. The third best locations to build wind turbines would be along the east coast extending northward from Georgia to Maine, the southeastern tip of Texas, the Great Lakes Region, and just offshore Southern California and Washington State. And parts of the Midwest would also be considered a third best location for wind resources. Based on observations from surface stations and soundings in the US for year 2000, Archer and Jacobson [1,2] analyzed the spatial distribution of the US wind classes at a height of 80 meters. Their results show that one of the greatest promising continental locations for wind power was found to be located in what is referred to as the "central belt" of the US. 
The central belt includes the states of Oklahoma, Nebraska, Kansas, South Dakota, and North Dakota. The southern and eastern coasts also provide good potential, especially offshore. The average wind power class of the Great Lakes Region is 6, which is a wind potential shared between both Canada and the US. Also, according to Li et al. [3], the Great Lakes Region is currently an excellent candidate for the development of wind energy since there are large unobstructed and open areas available for construction.

Although the assessment of wind energy resource distribution has already been intensely conducted under current climate, it is important to conduct further research on the variability of wind resources in climate that is continuously changing. In addition, it is imperative to understand how wind resources will change and evolve in the future climate setting, since wind energy is a massively growing industry with constant pressure to meet state and federal mandates for increased use of renewable energy supplies [4]. It needs to be noted that although a particular location may presently be a good candidate for a wind farm, it may not be in the future due to climate change. Therefore, it is necessary to forecast where the best wind resources will be not only in the present climate but also in the future climate, in order to obtain the best possible future usage. Finally, it is vital to understand how climate change may affect wind energy sources across the US under future climate scenarios.

The Intergovernmental Panel for Climate Change (IPCC) Fourth Assessment Report (AR4) leaves no doubt that the increase in greenhouse gas emissions will lead to significant environmental changes in all regions of the globe [5]. However, the degree of uncertainty of the projected climate change increases from global scale to regional scale. Most of the AOGCMs do not have high enough resolution to see the regional and small-scale topographic features. To project the large-scale climate changes onto regional scales, several climate change downscaling techniques, including statistical (or empirical) downscaling and dynamical downscaling, have been developed in recent years [6-8].

Statistical downscaling methods exploit existing statistical relationships between large-scale climate processes and their regional manifestations. These relationships are typically derived from present-day observations and it is assumed that these relationships remain stationary in time. The same relationships that are derived from present-day observations are assumed to be valid under greenhouse warming conditions. Dynamical downscaling uses high resolution regional models which are forced by global models with coarse resolution under both current climate and projected future climate scenarios. The dynamical model combines the coarsescale boundary forcing with internal dynamics in a physically consistent way. In dynamical downscaling, regional models are nested in global models by specifying lateral boundary conditions through a traditional "sponge zone" technique using a relaxation procedure [9]. However, this conventional nesting-down method inevitably distorts the information transmitted from the global model to the regional model. Large-scale features are more accurately simulated in the global model, while small-scale ones are better captured in high resolution regional models.
Several alternate approaches in addition to the conventional nesting technique were developed in downscaling regional modeling studies. The "perturbation method" was used in nesting the NCEP regional spectral model within a global spectral model, through which the perturbation obtained from the regional model is added to the large-scale base state from the global model to compose the full field in the regional model (e.g., [10]). A similar "spectral nudging" approach $[11,12]$ was utilized to provide large-scale forcing in the regional model domain interior to ensure that the large-scale circulation in the regional models was consistent with that from the global analyses or forecasts. More recently, Peng et al. [13] introduced a scale-selective data assimilation (SSDA) approach in downscaling from global models to regional models by driving the regional model from the regional model domain interior as well as by specifying the lateral and lower boundary conditions. The SSDA dynamical downscaling approach has been demonstrated to improve seasonal climate hindcasting for the North Atlantic Basin and Eastern United States [13] as well as to improve tropical cyclone simulation and forecasting $[14,15]$.

The objective of this study is to dynamically downscale the impacts of climate change on wind energy resources over the CONUS by using the SSDA approach. Wind energy under both current and future climate scenarios will be downscaled for the CONUS region. Assessment of climate change impacts on wind energy resources over the CONUS region will then be conducted. This will help detect the best locations to place wind turbines under both current and future climate situations, while utilizing wind energy efficiently under the circumstance of a continuously changing climate. A detailed description regarding the SSDA approach, model, data, and method used in this study is given in Section 2. Wind energy resource downscaling under current climate is presented in Section 3. In Section 4, wind energy downscaling results under future climate scenarios are provided. Also, comparisons among wind energy resources under current and future climate scenarios are conducted to assess climate change impacts on wind energy resources. Summary and conclusions are given in Section 5.

\section{Model, Data, and Method}

The LAM utilized in this study is the Weather Research and Forecasting (WRF) model [16, 17] version 3.2 with the Advanced Research WRF (ARW) core. It features a fully compressible, Eulerian and nonhydrostatic control equation set. The model uses the Arakawa- $\mathrm{C}$ grid and the terrainfollowing, hydrostatic-pressure vertical coordinate system. The time integration scheme is the third-order RungeKutta scheme. And for the spatial discretization there are second through sixth order advection schemes available in the model. WRF incorporates various physical processes including microphysics, cumulus parameterization, planetary boundary layer (PBL), surface layer, land surface, and longwave and shortwave radiations.

The SSDA approach developed by Peng et al. [13], Xie et al. [14], and Liu and Xie [15] is employed as the dynamical downscaling technique. The SSDA system consists of the WRF 
model, a three-dimensional variational data assimilation (3DVAR) technique [18] from WRF model data assimilation (WRFDA) system, and a low-pass filter to separate the largeand small-scale components for both global and regional model forecasts. WRF-3DVAR from WRFDA is based on an incremental variational data assimilation technique which is used to assimilate the large-scale information from the global model into the regional model. Discrete fast Fourier transform (FFT) together with a detrending program dealing with aperiodic lateral boundary is used to separate large- and small-scale information for both the global and the regional models. In Peng et al. [13], the SSDA approach was applied in a seasonal climate hindcasting for the North Atlantic basin and Eastern United States, in which comparisons against global and regional analysis data have shown that the SSDA approach can benefit from the merits of both global models in representing large-scale environmental flows and regional models in describing small-scale characteristics with high resolution, resulting in improvements in the overall regional model simulations. Besides, in the applications in tropical cyclone hindcasting and forecasting [14, 15], the SSDA approach has also been proved to effectively improve tropical cyclone track and intensity forecasting. More details about the SSDA system are referred to by Liu and Xie [15].

The model domain for the LAM used in this study is centered at $\left(38.0^{\circ} \mathrm{N}, 98.0^{\circ} \mathrm{W}\right)$, covering the CONUS region. It contains $163 \times 109$ grid meshes with a grid spacing of $36 \mathrm{~km}$ in the Lambert conformal map projection. The LAM has 30 sigma levels in the vertical direction with the model top at $50 \mathrm{hPa}$. The integration time step is 120 seconds. The following physics schemes are chosen: the WSM5 microphysics scheme [19], the Kain-Fritsch cumulus scheme [20], the Yonsei University (YSU) PBL scheme [21], the Noah Land Surface Model [22], and the CAM (NCAR Community Atmosphere Model) longwave and shortwave radiation schemes [23].

The LAM is driven by the global model results from IPCC CCSM3 with the lateral boundary conditions being updated every 6 hours. In addition, large-scale wind components above the 13th sigma level (about $850 \mathrm{hPa}$ ) from the global model are assimilated into the LAM every 2 days through the SSDA procedure, directly driving the LAM from the model domain interior. This practice of only constraining large-scale fields above the PBL (e.g., [12]) allows the LAM to adjust its low-level dynamics based on its own regional topography and land-sea characteristics.

The global model results from the Community Climate System Model version 3 (CCSM3) under the Intergovernmental Panel on Climate Change (IPCC)'s 20th century (20C3M) and SRESA1B climate scenarios which are used to drive the LAM. For current climate, the 20C3M experiment results from the CCSM3 are used to downscale current climate with a time period of 1990 to 1999 . For two future time periods (2040 to 2049 and 2090 to 2099), the CCSM3 results under the A1B scenario are used to drive the LAM.

In addition, the North American Reanalysis (NARR) data is used as an independent data set when validating the downscaling of wind energy resources under current climate conditions. NARR provides various atmospheric analyses
TABLE 1: Classifying wind energy at 10 meters based on wind speed $\left(\mathrm{m} \mathrm{s}^{-1}\right)$, wind power density $\left(\mathrm{W} \mathrm{m}^{-2}\right)$, and overall wind resource potential.

\begin{tabular}{lccc}
\hline $\begin{array}{l}\text { Wind power } \\
\text { class }\end{array}$ & $\begin{array}{c}\text { Resource } \\
\text { potential }\end{array}$ & $\begin{array}{c}\text { Wind speed } \\
\left(\mathrm{m} \mathrm{s}^{-1}\right)\end{array}$ & $\begin{array}{c}\text { Wind power } \\
\text { density }\left(\mathrm{W} \mathrm{m}^{-2}\right)\end{array}$ \\
\hline 1 & Marginal & $<4.4$ & $<100$ \\
2 & Marginal & $4.4-5.1$ & $100-150$ \\
3 & Fair & $5.1-5.6$ & $150-200$ \\
4 & Good & $5.6-6.0$ & $200-250$ \\
5 & Excellent & $6.0-6.4$ & $250-300$ \\
6 & Outstanding & $6.4-7.0$ & $300-400$ \\
7 & Superb & $>7.0$ & $>400$ \\
\hline
\end{tabular}

with relatively high temporal (3 hour) and spatial $(32 \mathrm{~km})$ resolution for North America and nearby land masses and oceans from the time period of October 1978 to the present. Another data set used to validate the wind energy resource downscaling under current climate in this study comes from the surface wind measurements from various surface observation platforms collected by NCDC.

To assess wind energy resources, several metrics including surface wind speed at $10 \mathrm{~m}$ height, wind power density, and wind energy resource class are used in this study. Wind power density is the rate at which wind energy transmits through a unit of space or area. Wind power density can be expressed as power $(P)$ over area $(A): P / A=(1 / 2) \rho v^{3}$, where $\rho$ is air density and $v$ is wind speed. Wind power density provides an overall estimation of wind resource potential over a specific region. As for wind energy resource classification, according to the Wind and Water Power Program (2008) under the US Department of Energy, wind power is classified into seven classes ranging from class 1 to class 7 . Table 1 shows the criteria for each wind power class at a height of $10 \mathrm{~m}$. Each class is characterized by a particular resource potential, wind power density, and wind speed. However, classes 3 to 7 are the 5 main classes looked at since the first and second classes are marginal and not suitable for wind energy development on a utility scale.

\section{Wind Energy Resource Downscaling under Current Climate}

Before conducting regional downscaling, wind energy resources under current climate are assessed based on CCSM3 20C3M global model results for 1990s. Figure 1 shows the annual average wind speed, wind resource classification, and wind power density in the CONUS region from CCSM3 20C3M global model results during 1990 to 1999. It is revealed that the greatest wind speeds are between 6 and $8 \mathrm{~m} \mathrm{~s}^{-1}$ and correspond to the west and east coasts, the Great Plains region, and over parts of the Great Lakes Region. Most of the CONUS region has an average of $5 \mathrm{~m} \mathrm{~s}^{-1}$ average annual wind speed. The lowest wind speeds correspond to the southeastern US with values of around $4 \mathrm{~m} \mathrm{~s}^{-1}$. From the wind resource classification for current climate based 


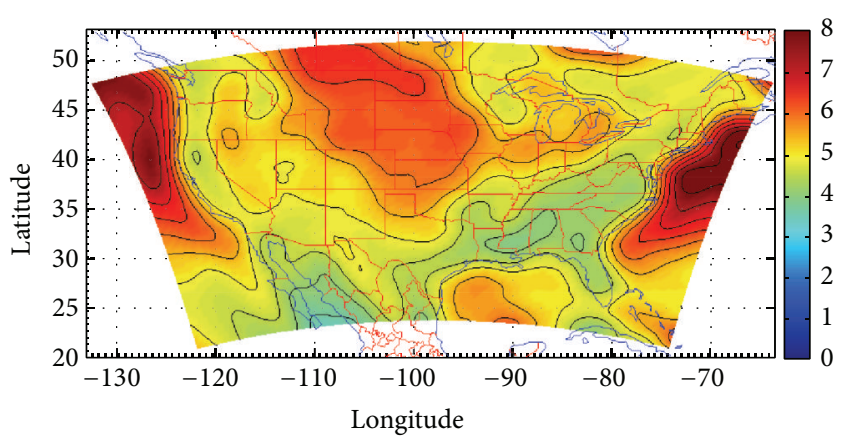

(a)

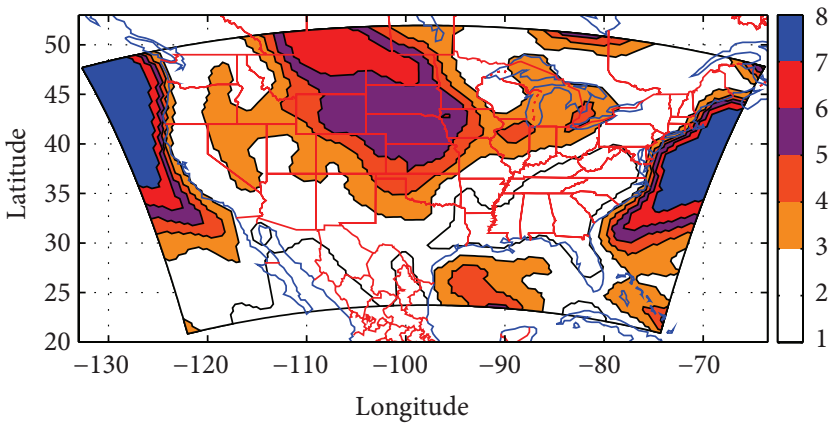

(b)

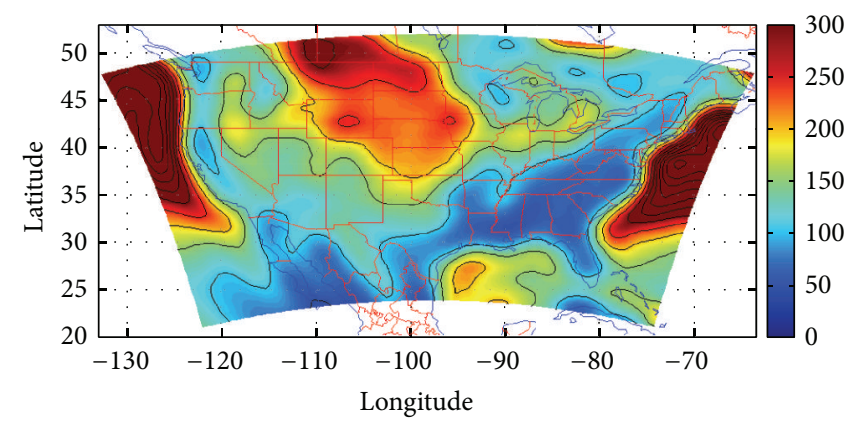

(c)

FIGURE 1: (a) Average annual wind speed $\left(\mathrm{m} \mathrm{s}^{-1}\right)$, (b) wind resource classification, and (c) average annual wind power density $\left(\mathrm{W} \mathrm{m}^{-2}\right.$ ) based on CCSM3 data in the CONUS region for current climate (1990-1999).

on CCSM3 20C3M global model results (Figure 1(b)), one can see that the most superb winds or class 8 winds correspond to the Atlantic and Pacific Ocean while class 7 winds correspond to the northern most section of the Great Plains (North Dakota and Montana) region as well as along the western and eastern coastal regions. Correspondingly, the wind power density is as great as $300 \mathrm{~W} \mathrm{~m}^{-2}$ over the Great Plains region and coastal regions. In contrast, the wind power density is as low as $50 \mathrm{~W} \mathrm{~m}^{-2}$ over the southeastern portion of the US. In between these regions and across the rest of the CONUS, there is an average of $100-200 \mathrm{~W} \mathrm{~m}^{-2}$ of wind power density. Although an overall general assessment of average annual wind speed, wind resource classification, and average annual wind power density can be made for current climate from the CCSM3 global model results, detailed regional features are missing in the global model results with relatively low grid resolution. That is why it is important to downscale the CCSM3 global model to a regional scale in order to get a better representation of the wind resources across the CONUS region.

Figure 2 gives the annual average wind speed, wind resource classification, and wind power density in the CONUS region for the SSDA downscaled CCSM3 20C3M global model results under current climate (1990-1999). It does an overall better job at capturing the regional scale features across the CONUS region as compared to Figure 1, before the SSDA downscaling was applied. Although the areas of maxima and minima wind speeds correspond to the same general locations as in Figure 1(a), Figure 2(a) reveals the influence of topography and small-scale geographical features that the SSDA downscaling picks up on in small subscale regions that the original CCSM3 data cannot. More specifically, the SSDA downscaled data reveals a more realistic representation of wind speeds over the Rocky Mountains and Great Lakes Region.

There is as great as a $3 \mathrm{~m} \mathrm{~s}^{-1}$ difference over these areas before downscaling takes place as opposed to after. If downscaling is not applied, the wind speeds will often be underestimated since the CCSM3 will skip over important subregions with differing topography. These differences can also be seen in Figure 2(b) which shows the wind resource classification. In Figure 1(b), there are nearly no regional scale topographical features shown whereas in Figure 2(b) these regional scale features are very clearly displayed. This is the same case for Figure 2(c) versus Figure 1(c) for average annual wind power density. Since wind power density is directly proportional to wind speed, the areas with differences are the same in this case.

In general, in order to get more realistic near-surface wind speeds, wind power classification, and wind power density, the LAM with higher spatial resolution downscaling from a global to a regional scale will outperform the global model, due to its better representation of regional characteristics for topography, land use, and so forth. Besides, the SSDA approach combines the merits for both the global model and the LAM, which will also help the LAM produce more accurate results. In the following comparisons between the original CCSM3 global results and the SSDA downscaled 


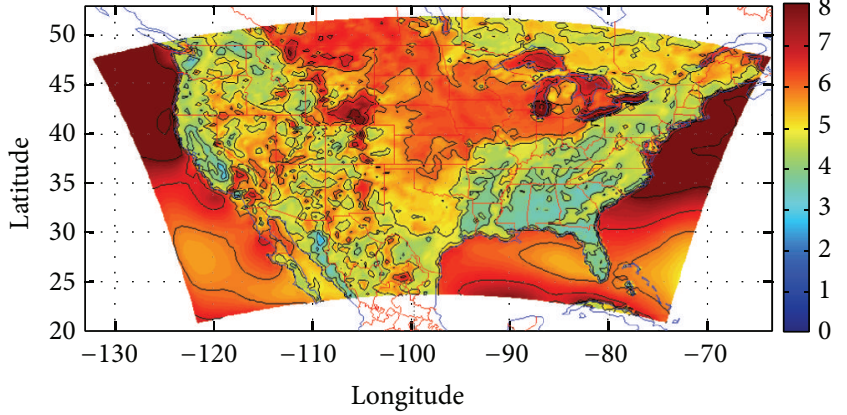

(a)

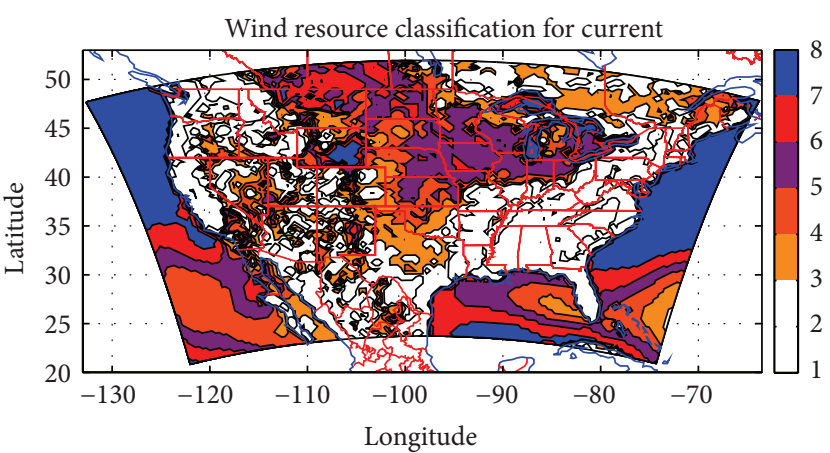

(b)

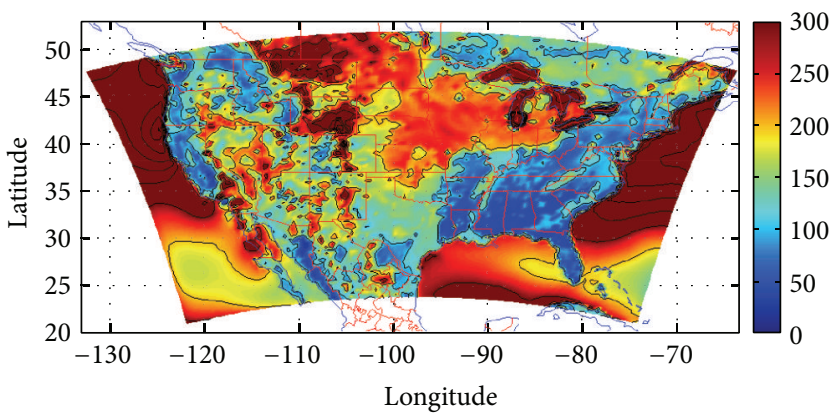

(c)

Figure 2: (a) Average annual wind speed $\left(\mathrm{m} \mathrm{s}^{-1}\right)$, (b) wind resource classification, and (c) average annual wind power density (W $\mathrm{m}^{-2}$ ) for SSDA downscaled simulation in the CONUS region for current climate (1990-1999).

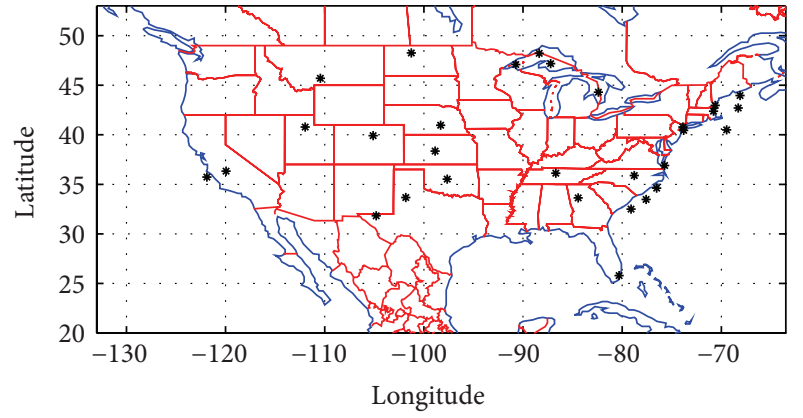

FIGURE 3: Locations of selected stations across the CONUS region used in this study for comparison.

regional results against the NARR data, some surface wind measurements from observation stations were made to show the benefit of the SSDA regional downscaling.

Comparisons were made among CCSM3 data, SSDA downscaled CCSM3, and NARR data for current climate (1990-1999) against 30 stations that were chosen across the US (see Figure 3 for the locations of the stations) in order to get an overall assessment of the accuracy of the data sources in terms of wind energy across the CONUS region. Regions of both high and low wind energy were selected.

Table 2 shows the actual wind speed of each station and is compared to the SSDA downscaled values, CCSM3 values, and NARR observational data values. In addition, the standard error (SE) is shown for each data set. SSDA has the second largest standard error value $(\mathrm{SE}=0.27)$ out of all 4 data sets, indicating rather large variability of wind speeds at each station location relative to the mean wind speed value. SSDA has the greatest standard error value for wind speeds in excess of $6 \mathrm{~m} \mathrm{~s}^{-1}$ with a value of 0.29 . This indicates even greater variability of wind speeds at each station location relative to the mean wind speed value.

The mean absolute error (MAE) of SSDA, CCSM3, and NARR in comparison to the station wind speed data is also shown in Table 2. SSDA revealed less MAE than both CCSM3 and NARR data overall. SSDA had an MAE of 1.27 whereas CCSM3 had an MAE of 1.43 and NARR 1.40, which means that SSDA showed an overall 11\% improvement over CCSM3 and an overall 9\% improvement over NARR. Although these percentages may not look like significant improvements, they are calculated for a 10-year average time span from 1990 to 1999 over 30 stations.

A closer look at the data reveals that the SSDA downscaled wind speed tends to improve over the global model simulation most significantly at higher wind speeds. For stations with high wind speeds $\left(>6 \mathrm{~m} \mathrm{~s}^{-1}\right)$, SSDA appears to have the most significant improvement over CCSM3 and NARR. SSDA had an MAE of 1.35, whereas CCSM3 had an MAE of 1.78 and NARR had an MAE of 1.88, which means that SSDA showed an overall $24 \%$ improvement over CCSM3 and an overall 29\% improvement over NARR. These improvements are very impressive because improvements over regions of abundant wind resources are particularly 


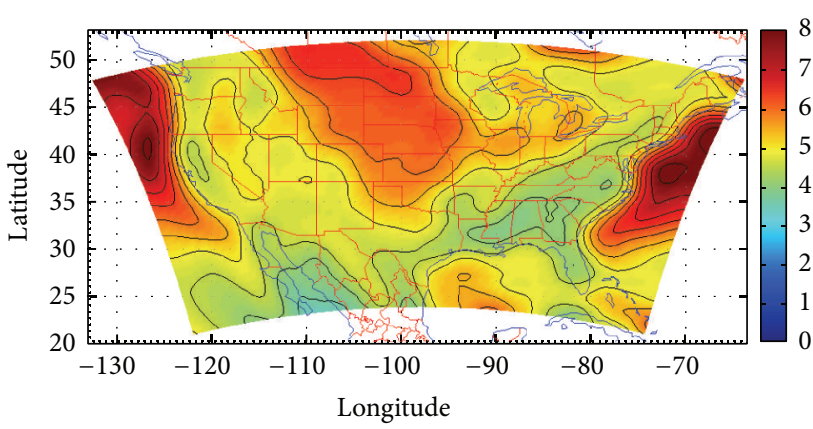

(a)

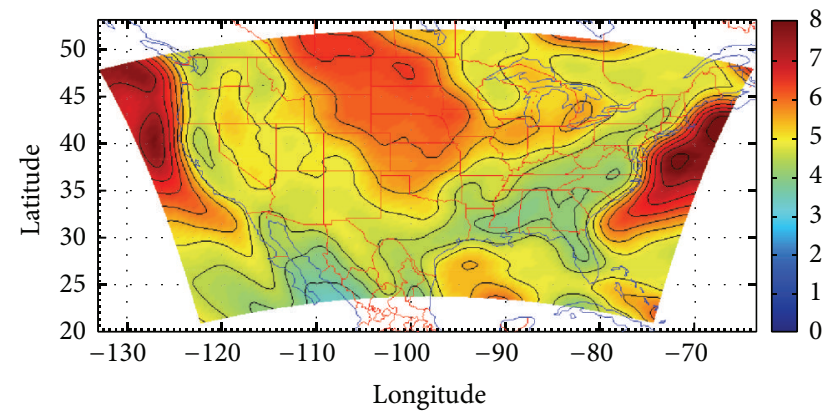

(b)

FIGURE 4: Average annual wind speed $\left(\mathrm{m} \mathrm{s}^{-1}\right.$ ) from CCSM3 data for (a) 2040s and (b) 2090s under the A1B climate scenario.

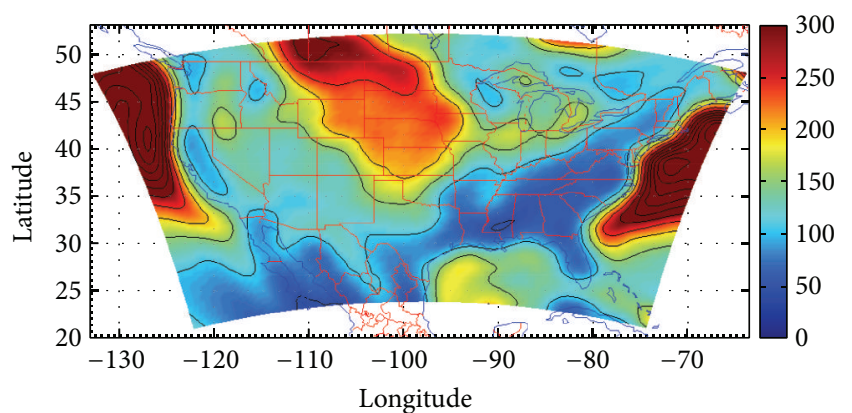

(a)

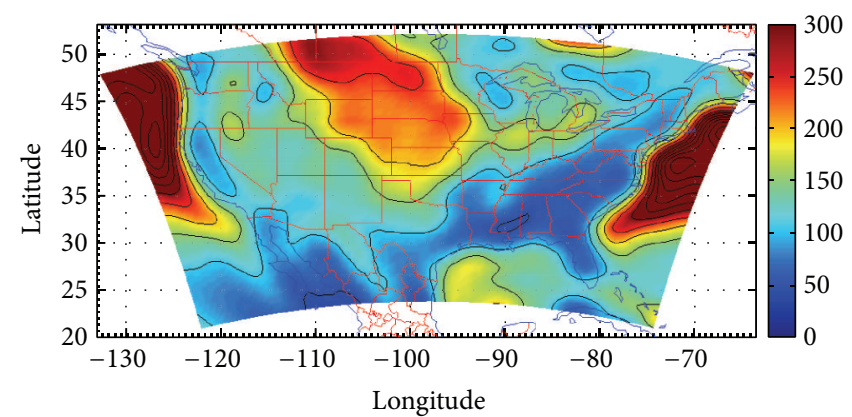

(b)

FIGURE 5: Average annual wind power density $\left(\mathrm{W} \mathrm{m}^{-2}\right)$ from CCSM3 data for (a) 2040s and (b) 2090s under the A1B climate scenario.

significant since these are regions in which wind energy engineering is most likely to be conducted.

\section{Wind Energy Resource Downscaling under Future Climate}

It has already been previously stated that downscaling is essential in order to capture regional scale features that GCMs cannot. Again, in this section, a comparison is made between the CCSM3 data and the SSDA downscaled CCSM3 data for the average annual wind speeds for the 2040s and 2090s. From the original CCSM3 global model projection results (e.g., Figure 4), it can be seen that the average annual wind speed distribution for the 2040s and 2090s looks very similar with maxima occurring over the Great Plains regions and coastal locations and minima occurring over the southeastern US. The average annual wind power density $\left(\mathrm{W} \mathrm{m}^{-2}\right)$ for the 2040s also resembles that for the 2090s (Figure 5). Since the wind power density is proportional to the wind speed cubed, the average annual wind power density does a better job of showing the contrast between high and low wind regions since the colors are more defined between the areas of maxima and minima wind speed.

However, when looking at the SSDA downscaled results (Figures 6 and 7), the regional scale features are easily visible across the CONUS region. Effects of topography and local-scale features across the US are evident due to the application of dynamical downscaling with the SSDA approach, providing a more realistic picture of the wind energy resources. More specifically, the regions of maxima and minima wind speed are more defined across the CONUS region when the regional scale features are able to be picked up by the SSDA downscaling methodology.

In order to assess the climate change impacts on wind energy resources, we further compare the SSDA downscaled wind energy resources under future climate with those under current climate conditions. Comparing Figures 6 and 7 with Figure 2, one can notice that the average annual wind speed experiences an overall shift across the CONUS region when projecting a few decades ahead into the future by means of following what is expected in IPCC's AlB scenario. The differences of the downscaled annual wind speed and annual wind power density between the future climate (2040s and 2090s) and the current climate decade (1990s) are shown in Figure 8, from which one can easily see where the average annual wind speed is expected to increase or decrease across the CONUS region.

According to Figure 8(a), over the next three decades, the average annual wind speed is expected to increase over the Great Plains, Northern Great Lakes, and Southwestern United States located southwest of the Rocky Mountains. A projected 0.1 to $0.2 \mathrm{~m} \mathrm{~s}^{-1}$ increase in mean wind speed is expected over these regions. Along the east coast, wind speeds remain fairly constant from the current climate to the 2040s. However, there is a slight decrease of up to $0.2-0.4 \mathrm{~m} \mathrm{~s}^{-1}$ over the Southern Great Lakes region, Rocky Mountains, 
TABLE 2: Annual mean wind speed comparison of SSDA downscaled CCSM3 data, CCSM3 raw data, and NARR data to station observations for current climate (1990-1999). Also, the standard error (SE) is shown for the observations, CCSM3, SSDA, and NARR data sets for all 30 stations as well as the 15 selected stations with wind speeds $>6 \mathrm{~m} \mathrm{~s}^{-1}$. Mean absolute error (MAE) for average annual wind speed for current climate (1990-1999) between raw CCSM3 data, SSDA data, and NARR data all compared to the station data. Also, the MAE for average annual wind speed greater than $6 \mathrm{~m} \mathrm{~s}^{-1}$ is calculated.

\begin{tabular}{|c|c|c|c|c|c|c|c|c|}
\hline Station name and statistics & State & ID number & Lat. & Lon. & OBS & CCSM3 & SSDA & NARR \\
\hline Frying Pan Shoals & $\mathrm{NC}$ & 994040 & 33.483 & -77.583 & 7.76 & 5.95 & 7.91 & 6.60 \\
\hline Cape Lookout & $\mathrm{NC}$ & 994160 & 34.617 & -76.517 & 5.86 & 5.88 & 7.21 & 6.31 \\
\hline Raleigh/Ral-Durham & $\mathrm{NC}$ & 723060 & 35.892 & -78.782 & 3.08 & 4.10 & 4.12 & 3.71 \\
\hline Env. Buoy 45008 & - & 992220 & 44.3 & -82.4 & 4.99 & 5.57 & 7.17 & 5.33 \\
\hline Stannard Rock & MI & 994200 & 47.183 & -87.217 & 8.38 & 5.44 & 7.30 & 5.62 \\
\hline Passage Island & MI & 994090 & 48.217 & -88.367 & 6.73 & 5.29 & 6.63 & 5.01 \\
\hline Devil's Island & WI & 994190 & 47.083 & -90.733 & 6.07 & 4.90 & 6.38 & 4.19 \\
\hline Oklahoma City/Wiley & $\mathrm{OK}$ & 723544 & 35.533 & -97.65 & 5.40 & 5.43 & 6.02 & 5.01 \\
\hline Lubbock/Lubbock INT & $\mathrm{TX}$ & 722670 & 33.666 & -101.823 & 5.55 & 5.34 & 5.28 & 4.59 \\
\hline Pine Springs Guadalupe & TX & 722620 & 31.831 & -104.809 & 8.33 & 4.76 & 5.45 & 5.70 \\
\hline Great Bend Muni & KS & 724517 & 38.35 & -98.867 & 5.24 & 6.07 & 6.37 & 4.30 \\
\hline Grand Island County & $\mathrm{NE}$ & 725520 & 40.961 & -98.314 & 5.04 & 6.22 & 6.25 & 4.28 \\
\hline Mission FLD & MT & 726798 & 45.698 & -110.441 & 7.04 & 5.88 & 6.93 & 3.44 \\
\hline Minot Intl & ND & 727676 & 48.255 & -101.273 & 5.24 & 6.63 & 6.30 & 4.04 \\
\hline Broomfield/Jeffco & $\mathrm{CO}$ & 724699 & 39.917 & -105.117 & 4.88 & 5.84 & 6.72 & 4.40 \\
\hline Salt Lake City INTL & UT & 725720 & 40.778 & -111.969 & 3.91 & 5.12 & 4.89 & 3.64 \\
\hline Env. Buoy 46028 & - & 992380 & 35.74 & -121.89 & 6.73 & 5.54 & 6.91 & 7.36 \\
\hline Lemoore NAS & $\mathrm{CA}$ & 747020 & 36.333 & -119.95 & 2.67 & 4.74 & 3.86 & 2.99 \\
\hline Miami & FL & 722020 & 25.791 & -80.316 & 3.91 & 4.89 & 4.91 & 3.68 \\
\hline Chesapeake & VA & 994020 & 36.9 & -75.717 & 7.35 & 5.38 & 8.43 & 5.53 \\
\hline Atlanta Hartsfield INTL AP & GA & 722190 & 33.63 & -84.442 & 3.91 & 4.08 & 4.49 & 3.61 \\
\hline Nashville/Metropoli & $\mathrm{TN}$ & 723270 & 36.119 & -86.689 & 3.39 & 4.22 & 4.15 & 3.30 \\
\hline Ambrose Light & NY & 994100 & 40.45 & -73.8 & 7.81 & 5.57 & 5.80 & 5.34 \\
\hline New York/La Guardia & NY & 725030 & 40.779 & -73.88 & 5.29 & 5.18 & 3.91 & 5.01 \\
\hline Isle of Shoals & $\mathrm{NH}$ & 994270 & 42.967 & -70.617 & 7.14 & 5.72 & 6.68 & 5.33 \\
\hline MT Desert Rock & $\mathrm{ME}$ & 994060 & 43.967 & -68.117 & 7.81 & 6.49 & 8.84 & 5.91 \\
\hline Env. Buoy 44005 & - & 992760 & 42.7 & -68.3 & 6.68 & 7.79 & 8.95 & 6.79 \\
\hline Env. Buoy 44008 & - & 992790 & 40.5 & -69.467 & 6.53 & 7.84 & 8.73 & 7.00 \\
\hline Env. Buoy 44013 & - & 992420 & 42.383 & -70.783 & 6.12 & 5.92 & 6.50 & 5.21 \\
\hline Edisto & - & 992730 & 32.5 & -79.1 & 6.58 & 5.72 & 7.51 & 6.28 \\
\hline SE & - & - & - & - & 0.29 & 0.16 & 0.27 & 0.22 \\
\hline SE for wind speeds $>6 \mathrm{~m} / \mathrm{s}$ & - & - & - & - & 0.19 & 0.23 & 0.29 & 0.27 \\
\hline MAE & - & - & - & - & - & 1.43 & 1.27 & 1.40 \\
\hline MAE for wind speeds $>6 \mathrm{~m} / \mathrm{s}$ & - & - & - & - & - & 1.78 & 1.35 & 1.88 \\
\hline
\end{tabular}

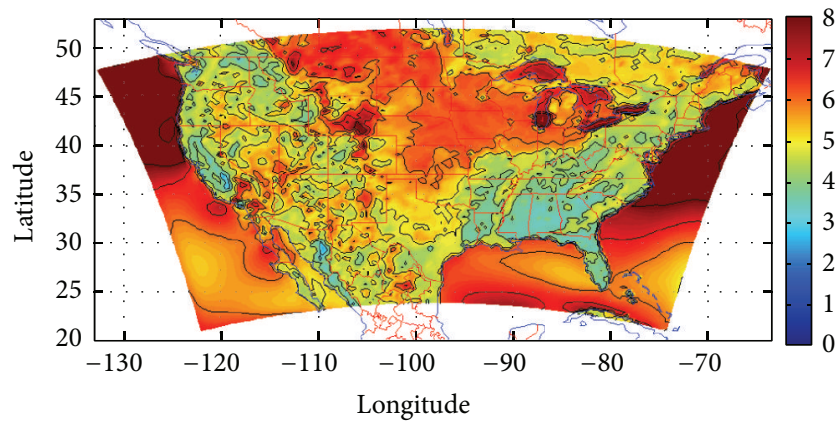

(a)

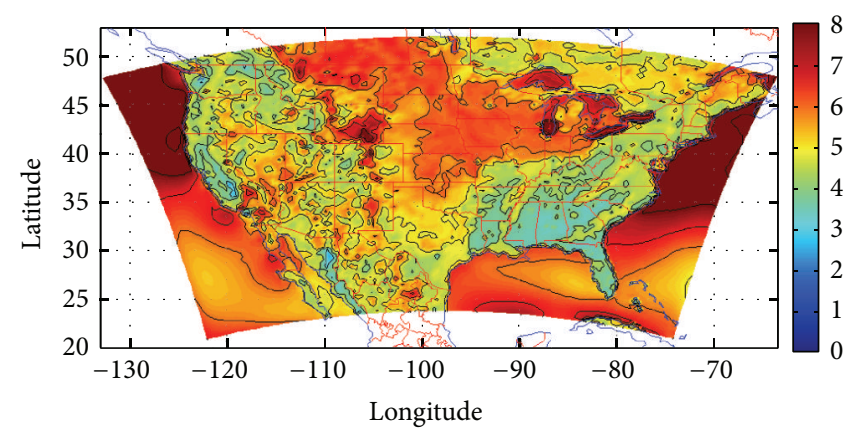

(b)

FIGURE 6: Dynamical downscaled average annual wind speed $\left(\mathrm{m} \mathrm{s}^{-1}\right)$ from CCSM3 for (a) 2040s and (b) 2090s under the A1B climate scenario. 


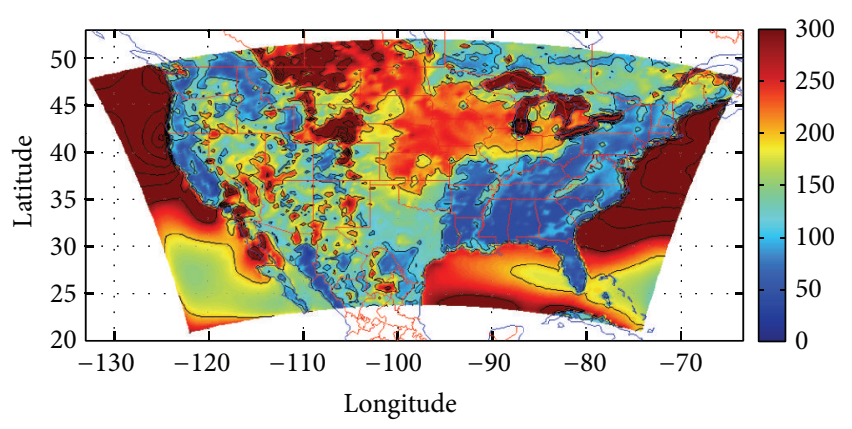

(a)

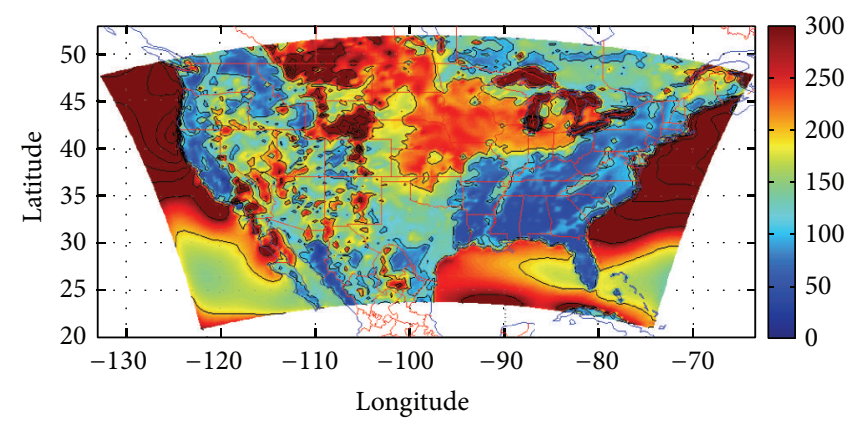

(b)

Figure 7: Dynamical downscaled average annual wind power density ( $\mathrm{W} \mathrm{m}^{-2}$ ) from CCSM3 for (a) 2040s and (b) 2090s under the A1B climate scenario.

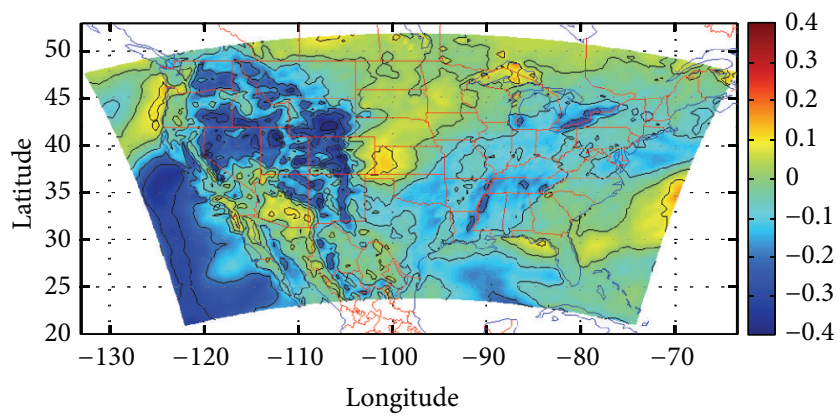

(a)

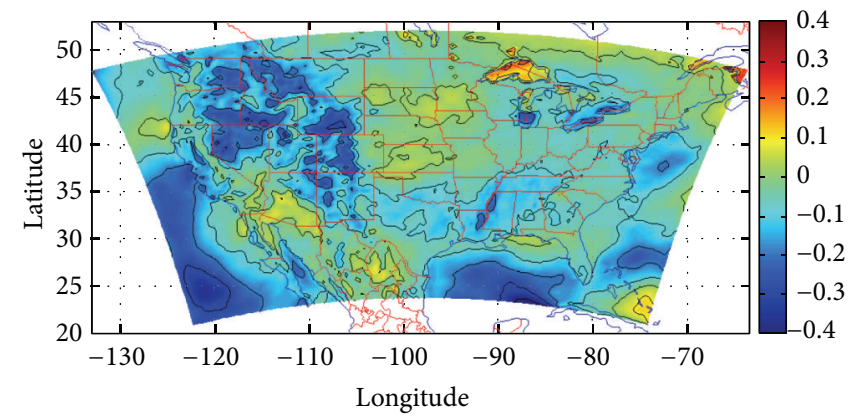

(b)

FIGURE 8: (a) Difference of average annual mean wind speed $\left(\mathrm{m} \mathrm{s}^{-1}\right)$ between 2040s and 1990s (current climate) and (b) difference of average annual mean wind speed $\left(\mathrm{m} \mathrm{s}^{-1}\right)$ between 2090s and 1990s (current climate).

and along the southeastern states west of the Appalachian Mountains including the states of Kentucky, Tennessee, Alabama, and Mississippi. The southeastern states east of the Appalachian Mountains remain fairly constant.

When projecting further ahead into the 2090s decade, by means of following what is expected in IPCC's A1B scenario (Figure $8(\mathrm{~b})$ ), the average annual wind speed also experiences an overall shift across the CONUS region as compared to current climate. There is an overall increase in the Great Plains region and Southwestern United States located southwest of the Rockies. However, the mean wind speed only increases between 0 and $0.1 \mathrm{~m} \mathrm{~s}^{-1}$ from the current climate to the 2090s. However, the Northern Great Lakes region experiences a greater increase in mean wind speed anywhere from 0.1 to $0.4 \mathrm{~m} \mathrm{~s}^{-1}$. Along the east coast, wind speeds experience a slight decrease of about $0.1 \mathrm{~m} \mathrm{~s}^{-1}$. The Southern Great Lakes region and southeastern states west of the Appalachians decrease once again but only by 0.1 to $0.2 \mathrm{~m} \mathrm{~s}^{-1}$ as compared to current climate. Overall, the Rockies decrease by an average of 0.1 to $0.2 \mathrm{~m} \mathrm{~s}^{-1}$. However, there are a few small spots along the Rockies that experience a decrease of around $0.3 \mathrm{~m} \mathrm{~s}^{-1}$. The southeastern states east of the Appalachian Mountains remain fairly constant for the most part, except for a very few areas that experience a slight decrease anywhere between 0 to $0.1 \mathrm{~m} \mathrm{~s}^{-1}$.

Therefore, overall, there is a more significant shift in wind speeds from the current climate to the 2040s versus the current climate to the 2090s over the majority of the CONUS region with only one noticeable exception taking place over the Northern Great Plains region.

In addition to comparing the future climate decades to current climate across the CONUS region as a whole, four subregions are chosen in order to get a closer look at how the wind speeds are expected to change in these selected regions throughout time. The four subregions chosen were as follows:

(1) Southeastern US (lon $>-90$, lon $<-82$, lat $>30$, and lat $<38$ ).

(2) Rocky Mountains (lon $>-114$, lon $<-106$, lat $>37$, and lat $<45)$.

(3) North Carolina (lon $>-85$, lon $<-75$, lat $>33$, and lat $<37)$.

(4) Great Plains (lon $>-102$, lon $<-98$, lat $>36$, and lat $<40$ ).

Figure 9 shows themean wind speed time series for these four subregions. As for the Southeastern US region, the average annual wind speed is plotted for current climate (1990s) and future climate decades 2040s and 2090s. The black and white points represent yearly mean wind speeds and the red points represent the overall 10-year averages for each decade. Based on the plotted red point, there is an evident decrease by about $0.1 \mathrm{~m} \mathrm{~s}^{-1}$ in the 10 -year average wind speed from the 1990s to the 2040s and then the wind 


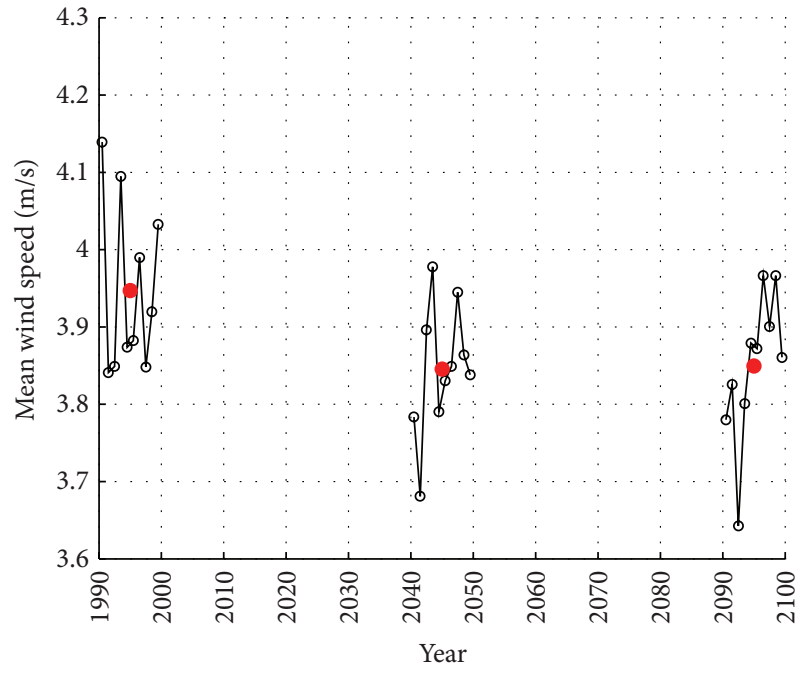

(a)

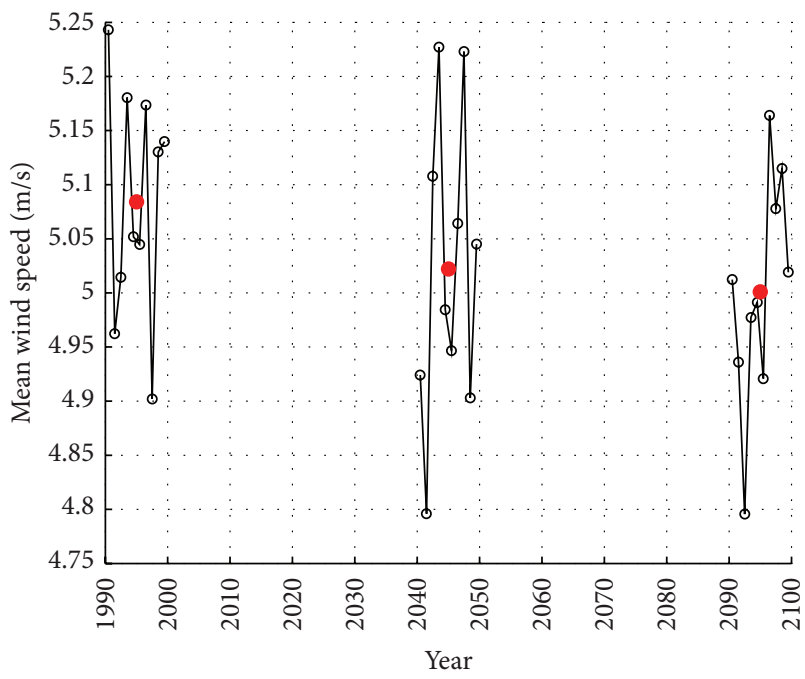

(c)

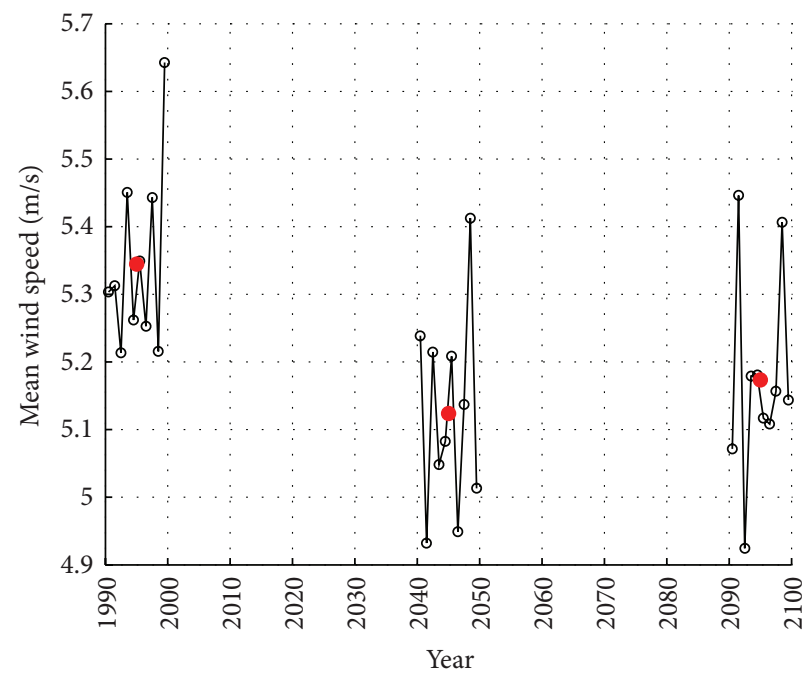

(b)

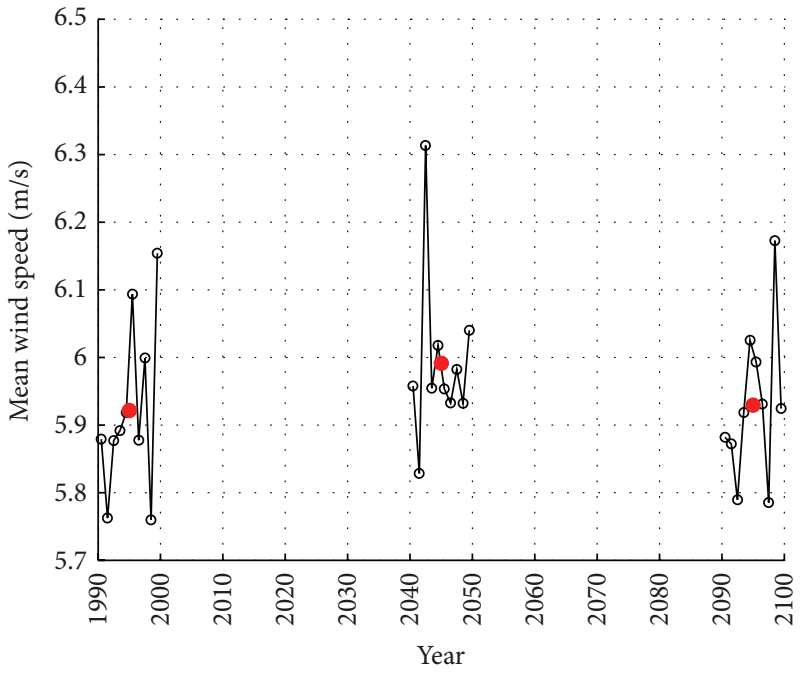

(d)

Figure 9: Mean wind speed $\left(\mathrm{m} \mathrm{s}^{-1}\right)$ time series for the (a) southeastern US, (b) Rocky Mountains, (c) North Carolina, and (d) Great Plains regions. The average annual wind speed is plotted for current climate (1990-1999) and future climate decades 2040s and 2090s. The black and white points represent yearly mean wind speeds and the red points represent the overall 10 -year averages for each decade.

speed remains fairly constant from the 2040s to 2090s. For the Rocky Mountains region, the wind speed appears to decrease from around 5.35 to $5.1 \mathrm{~m} \mathrm{~s}^{-1}$ between the 1990s and 2040s. There is then a very slight increase of approximately $0.1 \mathrm{~m} \mathrm{~s}^{-1}$ from the 2040s to the 2090s, but this wind speed value is still smaller than for current climate. The mean wind speed time series for the North Carolina region experiences a slight decrease between the 1990s and the 2040s and then remains fairly constant from the 2040s to the 2090s with an average value of around $5 \mathrm{~m} \mathrm{~s}^{-1}$. And for the Great Plains region, the mean wind speed time series reveals a mean wind speed of approximately $5.9 \mathrm{~m} \mathrm{~s}^{-1}$ for the 1990s, and then the wind speed increases to around $6 \mathrm{~m} \mathrm{~s}^{-1}$ by the 2040s. This indicates an overall slight increase of approximately $0.1 \mathrm{~m} \mathrm{~s}^{-1}$ over the Great Plains region from current climate to the 2040s. Then, there is then a very slight decrease from the 2040s to the 2090s, but the overall wind speed in the 2090s is still larger than for current climate.

\section{Conclusion}

Accurately assessing wind energy resources and predicting the impacts that climate change has on them are essential in order to prevent further waste of fossil fuels and encourage new and improved renewable wind energy projects across the CONUS region. Regional dynamical downscaling of global climate models is beneficial due to its higher spatial resolution and better capturing of the regional scale features that the global models cannot. Besides, the new dynamical downscaling approach of scale-selective data assimilation (SSDA) in addition to the traditional sponge zone relaxation downscaling approach was introduced in this study for 
wind energy resource downscaling in the CONUS, which assimilates large-scale information from the global model to the LAM, combining the merits of both the global and the regional models.

The SSDA method was utilized to assess wind energy resources under current climate based on CCSM3 global data and also was used to project wind energy resources under future climate for the 2040s and the 2090s by means of following what is expected in IPCC's A1B scenario. This SSDA downscaling approach was demonstrated to make marked improvements in downscaling wind energy resources under current climate in the CONUS region. The distribution of the wind energy resources produced by the SSDA downscaling approach is more closely depicted to the actual observational wind energy resource under current climate (1990s) across the CONUS region, as compared to the other data sets (including the original global CCSM3 data and the NARR data) used in this study.

Wind energy resources under future climate were then compared with those of current climate to assess the climate change impacts on the evolution of wind energy resources in the CONUS region. It was found that the average annual wind speed experiences an overall shift across the CONUS region. From the current climate to the 2040s, the average annual wind speed is expected to increase over the Great Plains, Northern Great Lakes region, and Southwestern United States located southwest of the Rocky Mountains. A projected 0.1 to $0.2 \mathrm{~m} \mathrm{~s}^{-1}$ increase in mean wind speed is expected over these regions. Whereas, when projecting into the 2090s from current climate, there is an overall increase in the Great Plains region and Southwestern United States located southwest of the Rockies with a mean wind speed increase anywhere between 0 and $0.1 \mathrm{~m} \mathrm{~s}^{-1}$ from the current climate to the $2090 \mathrm{~s}$. However, the Northern Great Lakes region experiences an even greater increase from the current climate to the 2090s than over the first few decades, with a mean wind speed of anywhere from 0.1 to $0.4 \mathrm{~m} \mathrm{~s}^{-1}$.

It was also shown that the regional dynamically downscaled wind speeds tended to improve over the global model results, specifically at regions with higher wind speeds. Improvements over these regions of abundant wind resources are particularly significant since these are regions where wind energy engineering is most likely to be conducted. The findings in this study provide the knowledge necessary to renewable wind energy companies so that they know where to invest in new wind energy projects and what impacts climate change could have on the wind energy resources across the continental United States.

\section{Conflict of Interests}

The authors declare that there is no conflict of interests regarding the publication of this paper.

\section{Acknowledgments}

This study is partially supported by NC State University Strategic Research Initiatives (SRI) Program Grant and the
National Oceanic and Atmospheric Administration Climate Change Program via a subcontract (UF-EIES-1100031-NCS) from University of Florida.

\section{References}

[1] C. L. Archer and M. Z. Jacobson, "Spatial and temporal distributions of U.S. winds and wind power at $80 \mathrm{~m}$ derived from measurements," Journal of Geophysical Research D: Atmospheres, vol. 108, no. 9, pp. 10-20, 2003.

[2] C. L. Archer and M. Z. Jacobson, "Evaluation of global wind power," Journal of Geophysical Research D: Atmospheres, vol. 110, no. 12, 2005.

[3] X. Li, S. Zhong, X. Bian, and W. E. Heilman, "Climate and climate variability of the wind power resources in the Great Lakes region of the United States," Journal of Geophysical Research D: Atmospheres, vol. 115, no. 18, Article ID D18107, 2010.

[4] S. C. Pryor, R. J. Barthelmie, D. T. Young et al., "Wind speed trends over the contiguous United States," Journal of Geophysical Research D: Atmospheres, vol. 114, no. 14, Article ID D14105, 2009.

[5] S. Solomon, D. Qin, M. Manning et al., Climate Change 2007: The Physical Science Basis, Cambridge University Press, New York, NY, USA, 2007.

[6] H. Von Storch, E. Zorita, and U. Cubasch, "Downscaling of global climate change estimates to regional scales: an application to Iberian rainfall in wintertime," Journal of Climate, vol. 6 , no. 6, pp. 1161-1171, 1993.

[7] R. L. Wilby and T. M. L. Wigley, "Downscaling general circulation model output: a review of methods and limitations," Progress in Physical Geography, vol. 21, no. 4, pp. 530-548, 1997.

[8] J. Schmidli, C. M. Goodess, C. Frei et al., "Statistical and dynamical downscaling of precipitation: an evaluation and comparison of scenarios for the European Alps," Journal of Geophysical Research D: Atmospheres, vol. 112, no. 4, Article ID D04105, 2007.

[9] H. C. Davies, "A laterul boundary formulation for multi-level prediction models," Quarterly Journal of the Royal Meteorological Society, vol. 102, no. 432, pp. 405-418, 1976.

[10] H.-M. H. Juang and S.-Y. Hong, "Sensitivity of the NCEP Regional Spectral Model to domain size and nesting strategy," Monthly Weather Review, vol. 129, no. 12, pp. 2904-2922, 2001.

[11] K. M. Waldron, J. Paegle, and J. D. Horel, "Sensitivity of a spectrally filtered and nudged limited-area model to outer model options," Monthly Weather Review, vol. 124, no. 3, pp. 529-547, 1996.

[12] H. von Storch, H. Langenberg, and F. Feser, "A spectral nudging technique for dynamical downscaling purposes," Monthly Weather Review, vol. 128, no. 10, pp. 3664-3673, 2000.

[13] S. Peng, L. Xie, B. Liu, and F. Semazzi, "Application of scaleselective data assimilation to regional climate modeling and prediction," Monthly Weather Review, vol. 138, no. 4, pp. 13071318, 2010.

[14] L. Xie, B. Liu, and S. Peng, "Application of scale-selective data assimilation to tropical cyclone track simulation," Journal of Geophysical Research: Atmospheres, vol. 115, no. D17, 2010.

[15] B. Liu and L. Xie, "A scale-selective data assimilation approach to improving tropical cyclone track and intensity forecasts in a limited-area model: a case study of Hurricane Felix (2007)," Weather and Forecasting, vol. 27, no. 1, pp. 124-140, 2012. 
[16] W. C. Skamarock, J. P. Klemp, J. Dudhia et al., "A Description of the Advanced Research WRF Version 3," NCAR Technical Note NCAR/TN-475+STR, Boulder, Colorado, Colo, USA, 2008.

[17] W. Wang, C. Bruyère, M. Duda et al., WRF Version 3 Modeling System User's Guide, 2011.

[18] D. M. Barker, W. Huang, Y.-R. Guo, A. J. Bourgeois, and Q. N. Xiao, "A three-dimensional variational data assimilation system for MM5: implementation and initial results," Monthly Weather Review, vol. 132, no. 4, pp. 897-914, 2004.

[19] S.-Y. Hong, J. Dudhia, and S.-H. Chen, "A revised approach to ice microphysical processes for the bulk parameterization of clouds and precipitation," Monthly Weather Review, vol. 132, no. 1, pp. 103-120, 2004.

[20] J. S. Kain and J. M. Fritsch, "A one-dimensional entraining/detraining plume model and its application in convective parameterization," Journal of the Atmospheric Sciences, vol. 47, no. 23, pp. 2784-2802, 1990.

[21] S.-Y. Hong, Y. Noh, and J. Dudhia, "A new vertical diffusion package with an explicit treatment of entrainment processes," Monthly Weather Review, vol. 134, no. 9, pp. 2318-2341, 2006.

[22] F. Chen and J. Dudhia, "Coupling an advanced land surfacehydrology model with the Penn State-NCAR MM5 modeling system. Part I: model implementation and sensitivity," Monthly Weather Review, vol. 129, no. 4, pp. 587-604, 2001.

[23] W. D. Collins, "Description of the NCAR community atmosphere model (CAM 3.0)," NCAR Technical Note NCAR/TN464+STR, NCAR, Boulder, Colo, USA, 2004. 

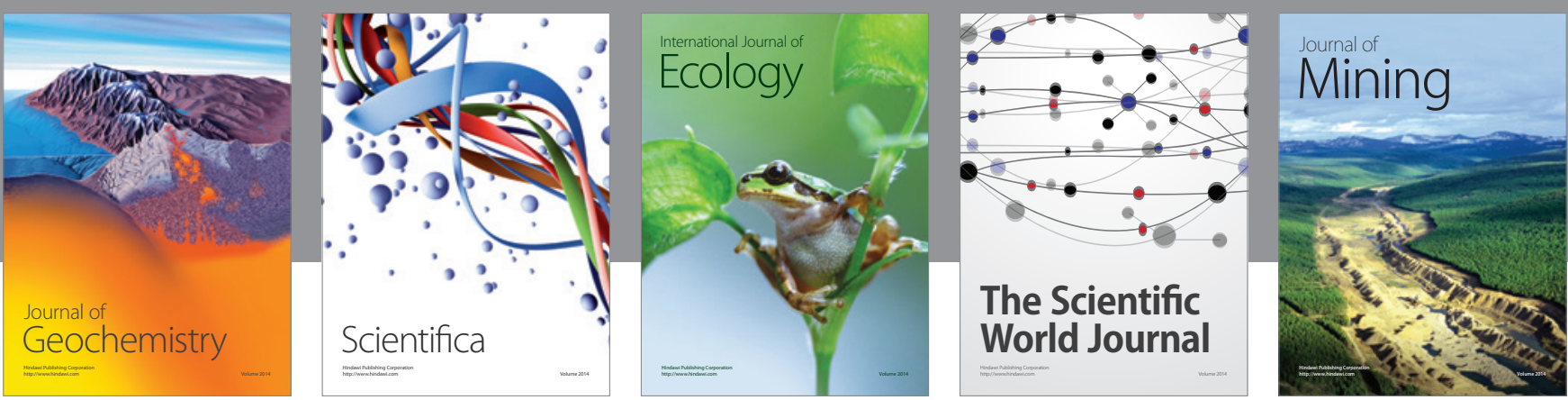

The Scientific World Journal
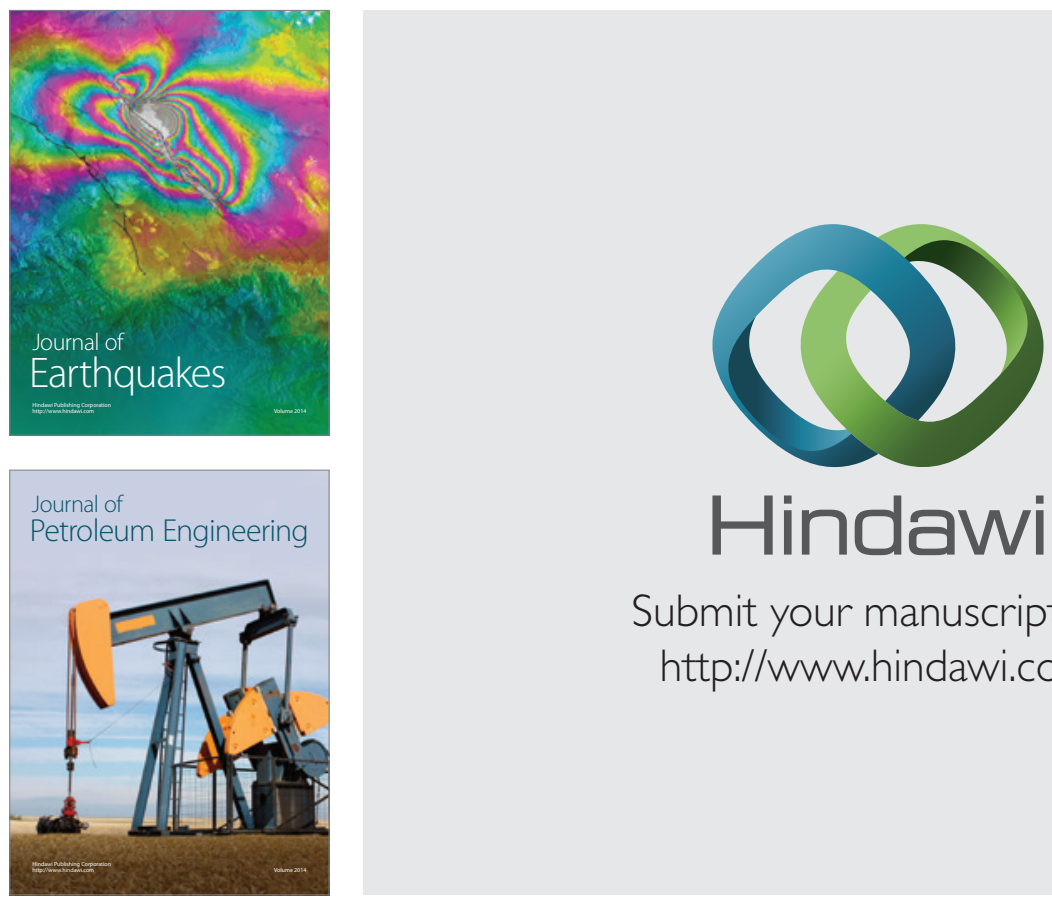

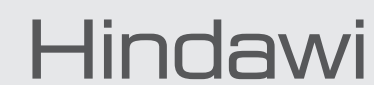

Submit your manuscripts at

http://www.hindawi.com
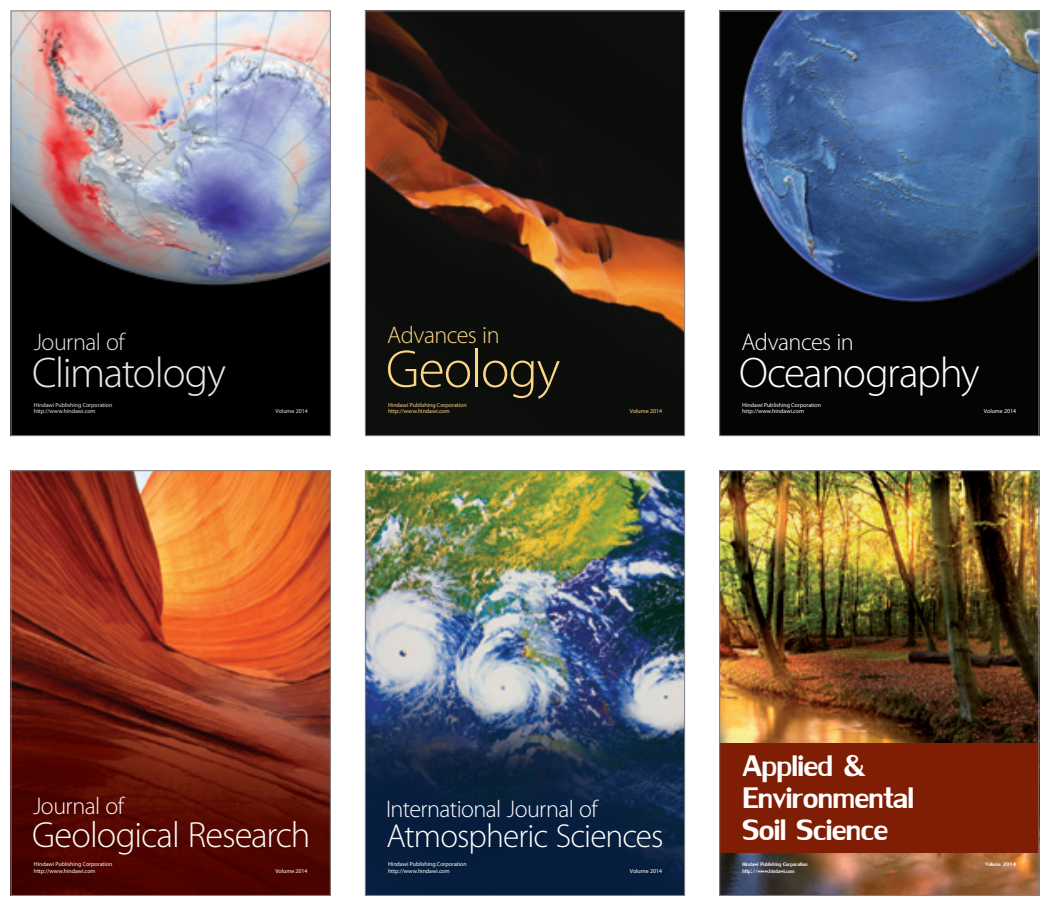
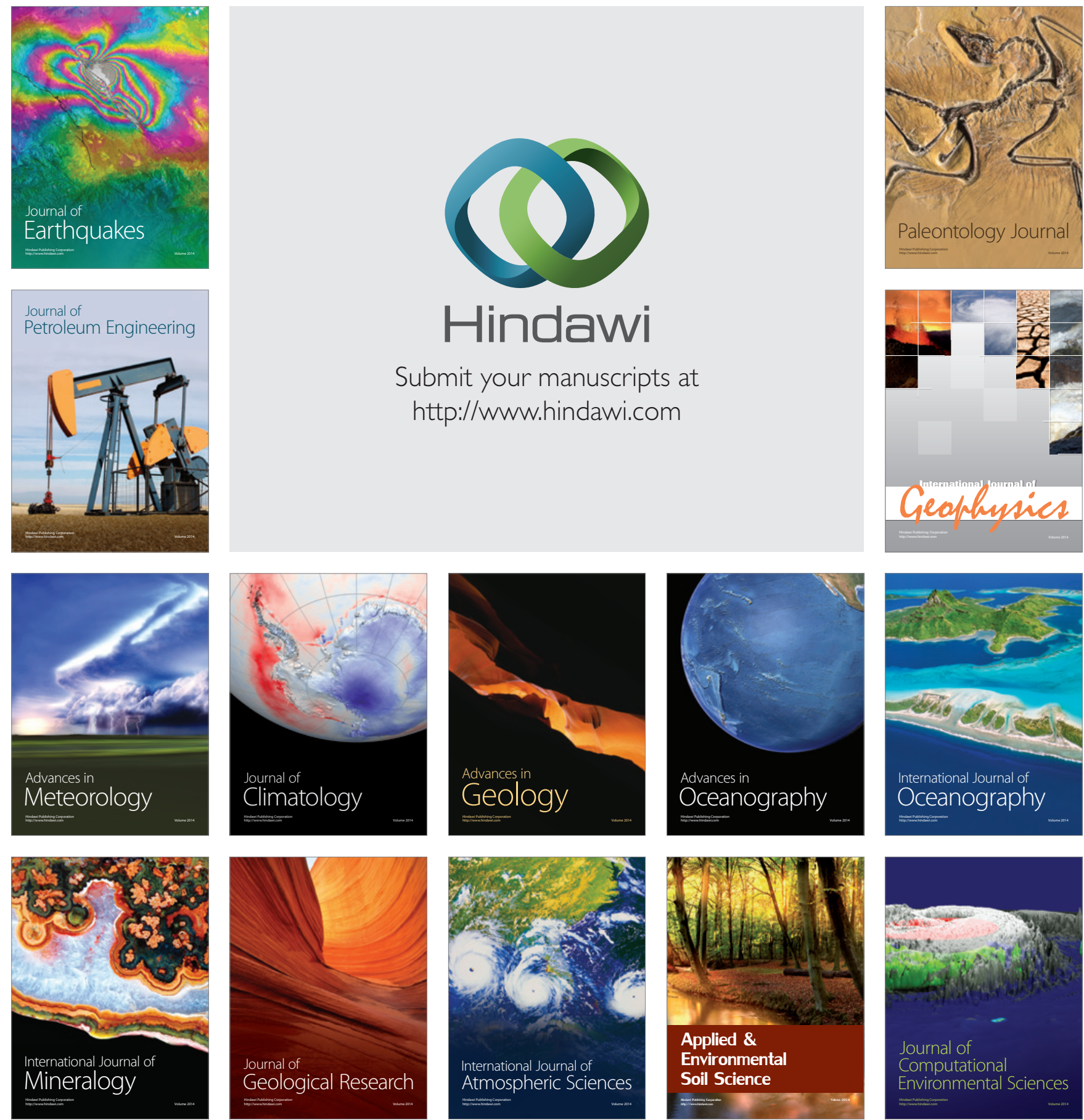